\title{
Understanding and countering terrorism
}

\author{
The steep rise in global terror necessitates a deeper scientific understanding of the terrorist profile and \\ evidence-based deradicalization programmes.
}

In the post-9/11 world, terrorist incidents have become much more frequent and more deadly (Global Terrorism Database; https://www.start.umd.edu/gtd/). More terrorist attacks have happened in May 2017 than during the entire year in 1970 . How did we get here and, more importantly, how do we go back?

The problem is incredibly complex: terrorism has multiple political, cultural, economic, and social facets, as well as individual psychological and ideological dimensions. Although political science, sociology and allied disciplines have made some headway in characterizing the political and socio-cultural circumstances that give rise to terrorism, we still know precious little about the psychological make-up of those who engage in terrorist acts or how we can successfully deradicalize them.

In this issue, Baez and colleagues (article number 0118) reason that examining the socio-cognitive profiles of terrorist groups could help us understand, and perhaps ultimately prevent, their atrocious practices. The authors examined the social and cognitive profiles of a unique sample: 66 incarcerated paramilitary terrorists in Colombia, a country where paramilitary groups have contributed to a dramatic growth of terrorist violence. All participants in this group were convicted of murder, with a mean of 33 victims per subject (but, as the authors note, most of them were responsible for several massacres, with death tolls sometimes exceeding 600 victims). Baez and colleagues administered a battery of socio-cognitive tests examining IQ, fluid intelligence, executive functions, aggression, emotion recognition and moral judgment to these incarcerated terrorists, as well as to a group of matched non-terrorists. They found that terrorists exhibited higher levels of aggression and lower levels of emotion recognition than non-criminals, but it was moral cognition that most strongly distinguished terrorists from non-criminal controls. When judging whether others' actions were morally permissible, terrorists focused primarily on outcomes, rather than integrating intentions and outcomes. Terrorists judged accidental harm as less permissible and attempted harm as more permissible, not only in comparison to nonterrorist controls, but also in comparison to incarcerated murderers with no terrorist background.

\section{We still know precious little about the psychological make-up of those who engage in terrorist acts or how we can successfully deradicalize them.}

Terrorist acts are widely viewed as being morally impermissible, but are supported by the logic that the ends justify the means. The study by Baez et al. provides insight into how terrorists perceive this trade-off and make moral judgments, which could ultimately lead to the development of instruments for prediction and rehabilitation.

The terrorists studied by Baez and colleagues were freed last year. Rehabilitation and reintegration of violent extremists into society is a significant challenge, however. As Daniel Koehler explains (article number 0095), although deradicalization programmes are the cornerstone of counter-terrorism strategies in several countries, few of these programmes are evidence-based or properly evaluated. The problem lies in the fact that the science, theory, and evidence lag behind the practice. But this is dangerous: it's not just a waste of money; poorly designed deradicalization programmes could backfire by giving away counterargumentation techniques or helping terrorists to re-enter society without raising the authorities' suspicion.

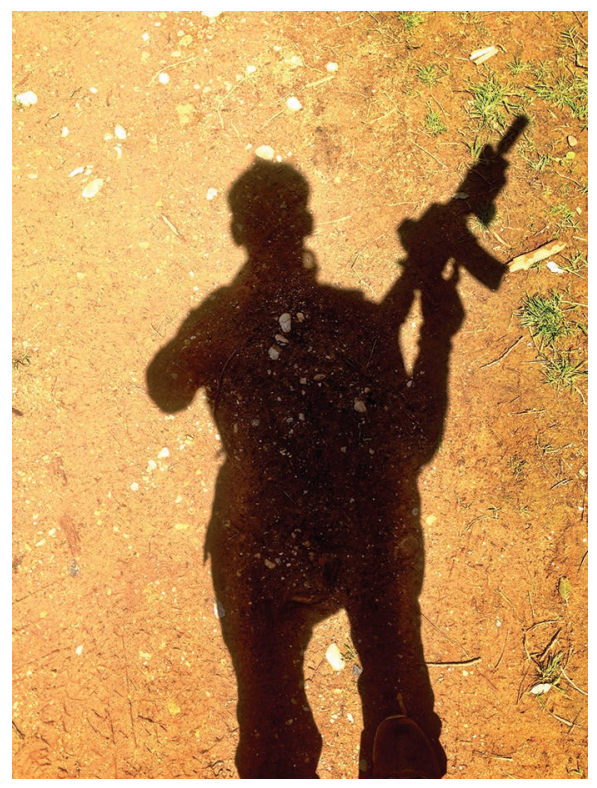

We are still ill-equipped to address one of the greatest challenges of our times. Ultimately, the global aim should be to remove the structural - political, economic, social, cultural - drivers that give rise to terrorism and violent extremism in the first place. Until then, however, more research into the ideological and psychological underpinnings of extremist behaviour is urgently needed, as is better integration between the science and the practice of deradicalization. 